\title{
Contraceptive use among Jamaican teenage mothers
}

\author{
Vonna Lou Caleb Drayton ${ }^{1}$
}

ABSTRACT Objective. To compare the prevalence of contraceptive use among teenage mothers who were participating, and teenage mothers who were not participating, in a program in Jamaica that had been established to deal with the country's serious problem of repeat pregnancies among adolescents.

Methods. A historical cohort design was used to assess the impact that the Women's Centre of Jamaica Foundation (WCJF) Programme for Adolescent Mothers had on contraceptive use among the target population of adolescents 16 years and under who had experienced a first live birth in 1994.

Results. Contraceptive use at first intercourse was found to be higher among WCJF program participants (44\%) than among nonparticipants (37\%), but this difference was not significant $(\mathrm{P}=0.35)$. Contraceptive use after first live birth was also higher among WCJF program participants (94\%) than among nomparticipants $(86 \%)$, and this difference was significant $(\mathrm{P}=0.04)$. Contraceptive prevalence at last intercourse (in 1998) did not differ between participants and nonparticipants (both 69\%).

Conclusions. Contraceptive use among this population in Jamaica was highest when the respondents' perception of vulnerability to pregnancy was most acute, that is, after the first live birth. All adolescents, both males and females, need to be educated about the importance of sustained and effective use of contraception in order to reduce the risk of unintended pregnancy and sexually transmitted diseases.

Key words Adolescence, contraception, pregnancy, patient education, Jamaica.

For at least several decades Jamaica has had a major national problem with adolescent pregnancy. As one response to that, in 1978 the Women's Centre of Jamaica Foundation (WCJF) Programme for Adolescent Mothers was established, with major financial

\footnotetext{
1 M.D. Anderson Cancer Center, Cancer Information Service, Houston, Texas, United States of America. Send correspondence to: Vonna Lou Caleb Drayton, 2914 Regata Run Drive, Friendswood, Texas 77546, United States of America; telephone: 281-648-0951; fax: 281-648-2274; e-mail: hdray68158@aol.com
}

support from the Government of Jamaica as well as donations from both local and international agencies. The activities of this WCJF program focus primarily on two areas. One area is providing classroom instruction and support for adolescent mothers 16 years and under, with two specific aims in mind: (a) to return them to the formal school system and (b) to delay the birth of a second child. The second area is working with mothers over 16 years old who are unmarried and/or unemployed, by helping them develop a variety of skills and assisting them with job placement (1).

Adolescent mothers 16 years and under, the study population of this analysis, are accepted into the WCJF program at any point during their first pregnancy and followed for 2 years after registration in the program. At the time of registration, the Centre solicits parental consent for program participants to obtain and use a family planning method postpartum. As part of the program, the WCJF provides medical consultation and referral for 
prenatal care during pregnancy and for a family planning method of choice after delivery. The young women also receive individual and group counseling, academic instruction, family life education, childcare services, and training in decision-making skills and parenting skills. Counseling aims to educate participants about their legal rights, the importance of family planning, the types of contraception available, and the prevention of sexually transmitted diseases.

Only adolescents with a first pregnancy are accepted. Some pregnant adolescents are referred to the program by previous participants. Other referrals come through informal community networks and from organizations, such as schools, churches, health centers, and legal services, that collaborate with and support the activities of the Centre (2). Between 1978 and 1995, each year an estimated $15 \%$ of all the adolescent mothers in Jamaica attended the WCJF program during their first pregnancy.

This paper will focus on the use of contraception to delay additional pregnancies, and it will compare the prevalence of contraceptive use among adolescent mothers who were participants in the WCJF program with that of nonparticipants. The data for this analysis were taken from a population-based historical cohort analysis of the impact of the WCJF program on repeat pregnancy among Jamaican teenage mothers 16 years and under who experienced a first live birth in 1994 as a result of their first pregnancy.

\section{Sexual activity among adolescents}

Caribbean society does not frown on premarital sex, and, according to Jagdeo (3), "early sexual activity and early childbearing are solid features of the adolescent landscape in the region." For most adolescents, regular sexual activity commences soon after puberty but prior to social maturity. Much of that sexual activity is casual, outside of formal unions, and devoid of social or emotional commitment. Among Jamaican males, there is sub- stantial peer group pressure to engage in sex in order to avert the stigma of homosexuality, and sexual initiation may occur as early as the age of 8 years (4).

Based on an analysis of records from the Jamaican National Family Planning Board, the 1993 Contraceptive Prevalence Survey report revealed that among young men and women overall, $16 \%$ of them were sexually active by age 14, $36 \%$ by age $16,61 \%$ by $17,77 \%$ by 18 , and $80 \%$ by age 20 (5). That same report also indicated that among women 15-19 years old, $60 \%$ of them had experienced sexual intercourse.

Therefore, sexual activity per se is not the real issue; rather, the problem is sexual activity that leads to pregnancy. Teenage fertility, according to Jagdeo (3), was never actively encouraged: "The Church preached against it; parents discouraged the idea and punished the fact; schools expelled pregnant girls from the classroom; [and] national governments have set up family life education units to deal with the problem." In the Caribbean, however, many pregnancies may be unplanned, but few babies are unwanted. Factors that exacerbate the problem of adolescent pregnancy include the earlier onset of puberty, earlier initiation of sexual activity, limited use of contraceptive techniques, and widespread ignorance about the structure and functioning of the human body, especially the male and female reproductive systems (6).

Among Jamaicans 15-24 years old, $80 \%$ of young women and $66 \%$ of young men received sex or family life education, most of it in school while between the ages of 14 and 17 (5). According to a literature review conducted by Chevannes (4), such education is associated with increased contraceptive use by females at first sexual encounter. In a study of the effect of sex education in schools in St. Kitts and Nevis, Russell-Brown and colleagues (7) concluded that, given the evidence of much sexual activity among teens, contraception is the most realistic option to avoid unwanted pregnancy.

\section{Contraceptive use among adolescents}

Consistent use of effective contraception requires an understanding of the consequences of unprotected sexual activity. Unfortunately, the inability of many adolescents to plan ahead and to anticipate the consequences of their actions leads to risk-taking behavior. As Hewell and Andrews (8) have noted, it is the adolescents' perception of risk rather than the actual risk itself that determines their use of contraception.

Contraceptive use among adolescents has been studied in many parts of the world. Research in Kenya indicated that contraception was viewed favorably by students of high socioeconomic status (9). Not only did these students recognize the adverse effects of an early pregnancy on their academic success and economic security, but they could also afford contraceptives. In South Africa, Setiloane (10) found fear of parental discovery to be a significant barrier to effective contraceptive use among teenage girls. In Nigeria, according to Alade (11), the sporadic nature of adolescents' sexual activity hindered determined and consistent use of contraception. In a study of students in Nova Scotia, Herold (12) made a similar observation: planning contraceptive use was much more difficult because the sexual activity was often spontaneous and episodic. Not unexpectedly, Herold also found that the highest proportion of unintended and unwanted pregnancies in his study population was among young women of low socioeconomic status, given that low-income women are less likely to be able to afford contraception.

In Latin America around 50\% of adolescents are sexually active, but only $14 \%$ of those sexually active young persons use any form of contraception (13). The Young Adult Reproductive Health Surveys showed that women in Latin America and the Caribbean who were 15-19 years old were more likely to use contraceptives if they were married, relatively older at first intercourse, educated, had had 
sex education, and lived in an urban setting (14).

According to the Statistical Institute of Jamaica, overall contraceptive use in that country increased from $38 \%$ in 1975 to $63 \%$ in 1993 (15). Nevertheless, in a 1993 literature review Chevannes (4) reported that some $60 \%$ of females and $90 \%$ of males still did not use any form of contraception at first intercourse.

Among sexually active Jamaicans aged $15-24,40 \%$ of females and $50 \%$ of males use some method of contraception (5). Among both sexes, contraceptive use increases with age and educational level. It is highest among urban residents, men of "medium" and "high" socioeconomic status, and women of "medium" socioeconomic status. However, among females 15-17 years old-an age group that includes some of the target population (12-16 years) of the Women's Centre-contraceptive use was a mere $19.2 \%$ in 1993.

\section{METHODOLOGY}

\section{Study design}

This study utilized a historical cohort design to assess the impact of the Women's Centre of Jamaica Foundation (WCJF) Programme for Adolescent Mothers on the prevalence of contraceptive use among their target population of adolescent mothers aged 16 years and under who experienced a first live birth in 1994 as a result of their first pregnancy. This study was conducted in 1998 and utilized the following data sources: vital records, Women's Centre program records, and self-reports from a survey. Abstraction of data from vital records and WCJF records provided a source of verification of key variables from the survey.

\section{Study population}

Study participants were females in four parishes: Kingston (which is also the capital city), St. Andrew, St. Catherine, and Manchester. (The Kingston
Metropolitan Area includes the city of Kingston and adjoining portions of the parish of St. Andrew.) The women were between the ages of 15 and 20 at the time of the survey in 1998 and they had had a first live birth in 1994, when they were between the ages of 11 and 16. According to an analysis done by the Government of Jamaica Registrar General's Office, from January through December 1994, 1453 births were registered for this target population: Kingston (746), St. Andrew (60), St. Catherine (379), and Manchester (268). There is a branch of the WCJF in each of these four locations.

\section{Sample size}

The total sample size needed was calculated to be 325 , based on a chisquare a priori analysis, with $95 \%$ power to detect significant differences between cases (program participants) and controls (nonparticipants), and an alpha of .05. In anticipation of a 50\% loss to follow-up because of the difficulties of finding individuals who might have migrated during the study period, the planned sample size was doubled to 650. A random sample of 650 birth records for this study population was abstracted from the birth registration files of the Registrar General's Office.

From this sample of 650 , we located 266 individuals, and 265 of them agreed to participate in the study. Parental and individual consent forms were utilized to secure permission for participants to be interviewed. Based on our reliability check, 5 of the 265 completed interviews were rejected, for two reasons: 2 of the births registered in 1994 were not first live births, and another 3 births occurred to teenagers who were older than 16 years at the time of delivery in 1994. The final sample was therefore 260, which represented $80 \%(260 / 325)$ of the originally planned sample size. This smaller sample size allowed us to detect significant differences between cases (program participants) and controls (nonparticipants) with approximately $90 \%$ power.

\section{Data abstraction}

Using a laptop computer and a portable scanner, one in every two birth records for the adolescent population 11-16 years from the parishes of Kingston, St. Andrew, Manchester, and St. Catherine who had had a first live birth in 1994 was scanned into the computer until a sample of 650 was obtained. All of the information contained in the birth record was manually transferred to a data file in SPSS version 7.5 statistical software (SPSS Inc., Chicago, Illinois, United States of America). The identification number on the birth record was used as the identification number for each questionnaire, and the names and addresses were used to find the individuals and to invite their participation in the survey. This unique identification number enabled us to link self-reports from the interviews with data abstracted from the birth records. We also reviewed WCJF records to identify those of this cohort of 650 adolescents who had participated in the WCJF program; the mother's age at delivery and her infant's date of birth were the unique identifiers used to match the two records.

\section{Survey}

Every effort was made to locate and make contact with all 650 members of the study cohort and to invite their participation in the survey. An attempt was made to trace each individual at no fewer than three addresses. The first address was identified from the data abstracted from the Registrar General's Department, and the second and the third were forwarding addresses within the study parishes that were provided by relatives, neighbors, and/or the local WCJF program office. We classified as "lost to follow-up" the members of the target population who could not be located after such careful tracking, who had migrated to parishes other than the ones included in this study, or who had migrated overseas. 


\section{Questionnaire}

The questionnaire used for data collection was developed by the author and constructed to measure those variables that reflect the types of change the WCJF program was intended to influence: avoidance of repeat pregnancies, completion of primary and/or secondary education, and contraceptive use. Some of the items in the questionnaire were selected from the 1993 Contraceptive Prevalence Survey of the Jamaica National Family Planning Board (5), and from studies conducted by Brown (16) and Chevannes (17) in their evaluation of the Women's Centre program. Items in this study that were used for measuring demographic variables and variables related to the WCJF program were selected so as to allow for comparisons with these previous studies.

Drafts of the questionnaire were reviewed by experienced social science researchers in Jamaica to ensure culture and language appropriateness, and the revised instrument was pretested using a random sample of 30 adolescent mothers from the sample population. After incorporation of all suggested revisions, the questionnaire was again pretested with a similarly constituted sample. Final revisions were made prior to administration of the instrument to the study cohort. Personal interviews were conducted with the assistance of a Jamaican consultancy firm, Hope Enterprises. This was the most appropriate strategy since this population cannot be readily contacted by telephone or regular mail. Female interviewers contracted to Hope Enterprises conducted the interviews at the home or work site of each of the young mothers.

\section{Variables}

The variables measured for this study included WCJF program participation during first pregnancy as well as use of contraception at first intercourse (prior to first pregnancy), use of contraception at last intercourse (that is, last intercourse prior to completion of survey in 1998), and use of contraception after first live birth (in 1994). Other study variables were: maternal age at time of first live birth ("FLB"), ethnicity, educational level at time of FLB, occupation of adolescent mother, household income (at FLB and time of survey), type of union/marital status with partner of FLB and current partner (at time of survey), age at first sexual encounter, age differential with first sexual partner, and family life education at home and at school prior to FLB in 1994. Demographic, birth record, and WCJF data abstracted from records were validated and updated in the questionnaire.

\section{Data analysis}

Data analysis was performed using the SPSS software. After checking for incorrect responses, missing values, and outliers, descriptive statistics were calculated for all variables. Crosstabulations and Pearson's chi-square tests were performed for all contraceptive use variables by WCJF program status (participant or nonparticipant) at time of first live birth in 1994 and by repeat pregnancy status (had or had not had one or two additional pregnancies) during the follow-up period of January 1995 through December 1998.

\section{RESULTS}

\section{Sample characteristics}

Characteristics of the total sample of 260 adolescent mothers are given in Table 1. Of the 260, one-third of them were WCJF program participants. A slight majority were from Kingston and St. Andrew parishes.

Slightly more than half of the respondents started having sex at either 14 or 15 years of age. For all but some $10 \%$ of the women, their first sexual partner had been older.

Eighty percent of respondents had received sex (family life) education in school prior to the first live birth in
1994. In addition, $49 \%$ of the women had received family life education at home, provided by: mothers (31\%); sisters $(5 \%)$; aunts (5\%); fathers $(2 \%)$; and others $(6 \%)$, including, grandparents, brothers, cousins, and friends (data not shown in table).

Some $60 \%$ of respondents did not use any contraception the first time they had sex; however, this figure was only $30 \%$ for the last time they had sex (that is, the last time before the survey in 1998). After the birth of the first child in 1994, nearly all the respondents $(96 \%)$ reported that they realized that they could prevent themselves from becoming pregnant a second time if they wanted to, but only $88.3 \%$ used contraception.

\section{Characteristics of WCJF program participants}

The study variables that were significantly associated $(P<0.05)$ with WCJF program participation are shown in Table 2. The WCJF program participants were more likely to have received family life education at home prior to their first pregnancy and to have used contraception after their first live birth in 1994. The participants were less likely to have experienced a repeat pregnancy during the followup period from 1995 to 1998.

\section{Contraceptive prevalence}

Participation in the WCJF program was not significantly associated with use of contraception at either first intercourse $(P=0.35)$ or at last intercourse $(P=0.95)$. Only contraceptive use after the first live birth showed significant association with WCJF program participation $(P=$ 0.04) (Table 2). Use of contraception was higher among WCJF program participants at first intercourse $(44 \%$ vs. $37 \%$ ) and after first live birth (94\% vs. $86 \%$ ), but prevalence did not differ by program status at last intercourse (both 69\%) (data not shown in tables). 
While the contraceptive methods chosen by WCJF participants and by nonparticipants did not differ at first intercourse, the methods did differ after the first live birth in 1994 (Table 3 ) and at last intercourse (Table 4). After the first live birth in 1994, a higher percentage of WCJF program participants used an intrauterine device $(27 \%$ vs. $1 \%)$, and a lower percentage used withdrawal (1\% vs. $6 \%)$ (Table 3). Only $6 \%$ of WCJF program participants reported not using a contraceptive method after the first live birth in 1994, as compared with $15 \%$ of nonparticipants. Use of contraceptive pills, which have lower user effectiveness than intrauterine devices, was higher among nonparticipants $(47 \%$ vs. $29 \%$ ). At last intercourse, a higher percentage of WCJF program participants used an intrauterine device $(12 \%$ vs. $2 \%$ ), and a lower percentage used withdrawal (1\% vs. $3 \%$ ) (Table 4$)$.

Table 5 presents information on contraceptive use variables significantly associated with repeat pregnancy. There were statistically significant differences between the respondents who had had a repeat pregnancy and those who had not in terms of contraceptive use at last intercourse and after first live birth. In addition, a higher percentage of respondents who experienced one or more additional pregnancies during the follow-up period of 1995 through 1998 did not use contraception at last intercourse and after first live birth.

\section{DISCUSSION}

The Women's Centre Programme for Adolescent Mothers is one initiative aimed at improving the "conditions of girls' lives" in Jamaica, and several small-scale studies have demonstrated its success in reducing the number of subsequent pregnancies among participants, compared with matched controls from the community. A matched case-control study of graduates from 1985-1995 conducted by Chevannes (17) concluded that program participants did far better than controls in terms of educational attain-
TABLE 1. Characteristics of 260 teenage mothers who participated in the study on contraceptive use, Jamaica, 1994-1998

\begin{tabular}{|c|c|c|}
\hline Variable & No. ${ }^{a}$ & $\% b$ \\
\hline \multicolumn{3}{|c|}{ Participating in Women's Centre of Jamaica Programme } \\
\hline Yes & 87 & 33.5 \\
\hline No & 173 & 66.5 \\
\hline \multicolumn{3}{|l|}{ Geographic distribution (parish) } \\
\hline Kingston & 131 & 50.4 \\
\hline St. Andrew & 8 & 3.1 \\
\hline St. Catherine & 79 & 30.4 \\
\hline Manchester & 42 & 16.1 \\
\hline \multicolumn{3}{|l|}{ Ethnicity } \\
\hline African descent & 232 & 89.0 \\
\hline Mixed & 22 & 9.0 \\
\hline Indian descent & 6 & 2.0 \\
\hline \multicolumn{3}{|l|}{ Maternal age at first live birth (1994) } \\
\hline 13 years & 11 & 4.0 \\
\hline 14 years & 41 & 16.0 \\
\hline 15 years & 99 & 38.0 \\
\hline 16 years & 109 & 42.0 \\
\hline \multicolumn{3}{|l|}{ Age of first sexual intercourse } \\
\hline$\leq 11$ years & 23 & 8.9 \\
\hline 12 years & 32 & 12.4 \\
\hline 13 years & 51 & 19.7 \\
\hline 14 years & 66 & 25.5 \\
\hline 15 years & 65 & 25.1 \\
\hline$\geq 16$ years & 18 & 6.9 \\
\hline \multicolumn{3}{|l|}{ Age differential of first sexual partner } \\
\hline Younger/Same age & 27 & 10.4 \\
\hline $1-2$ years & 62 & 23.8 \\
\hline $3-5$ years & 108 & 41.5 \\
\hline 6 or more years & 41 & 15.8 \\
\hline Don’t know & 17 & 6.5 \\
\hline Respondent refused to tell interviewer & 5 & 1.9 \\
\hline \multicolumn{3}{|l|}{ Family life education at home } \\
\hline Yes & 125 & 48.6 \\
\hline No & 130 & 50.6 \\
\hline \multicolumn{3}{|l|}{ Family life education at school } \\
\hline Yes & 200 & 79.6 \\
\hline No & 50 & 20.0 \\
\hline \multicolumn{3}{|l|}{ Contraceptive use at first intercourse } \\
\hline Yes & 96 & 37.0 \\
\hline No & 147 & 56.8 \\
\hline \multicolumn{3}{|l|}{ Type of contraception used at first intercourse } \\
\hline No method & 146 & 60.1 \\
\hline Condom & 79 & 32.5 \\
\hline Contraceptive pill & 6 & 2.5 \\
\hline Withdrawal & 5 & 2.1 \\
\hline Depo-Provera or other inject. contracept. & 4 & 1.6 \\
\hline IUD or coil & 2 & 0.8 \\
\hline \multicolumn{3}{|l|}{ Contraceptive use at last intercourse (1998) } \\
\hline Yes & 175 & 68.9 \\
\hline No & 78 & 30.7 \\
\hline \multicolumn{3}{|c|}{ Type of contraception used at last intercourse (1998) } \\
\hline No method & 76 & 30.0 \\
\hline Depo-Provera or other inject. contracept. & 86 & 34.0 \\
\hline Condom & 38 & 15.0 \\
\hline Contraceptive pill & 34 & 13.4 \\
\hline IUD or coil & 13 & 5.1 \\
\hline Withdrawal & 6 & 0.4 \\
\hline \multicolumn{3}{|l|}{ Contraceptive use after first live birth } \\
\hline Yes & 227 & 88.3 \\
\hline No & 30 & 11.7 \\
\hline
\end{tabular}


TABLE 1. (Continued)

\begin{tabular}{lrr}
\hline \multicolumn{1}{c}{ Variable } & No. $^{\mathrm{a}}$ & $\%^{\mathrm{b}}$ \\
\hline Type of contraception used after first live birth (1994) & & \\
No method & 30 & 11.6 \\
Contraceptive pill & 107 & 41.5 \\
Depo-Provera or other injected contraceptive & 49 & 19.0 \\
Condom & 36 & 14.0 \\
IUD or coil & 25 & 9.7 \\
Withdrawal & 11 & 4.3 \\
Repeat pregnancy during follow-up period (1995-1998) & 124 & 47.7 \\
None & 117 & 45.0 \\
One & 19 & 7.3 \\
Two & & \\
\hline
\end{tabular}

a Totals may not add up to 260 due to exclusion of missing values.

b Percents may not add up to 100 due to rounding and/or exclusion of missing values.

TABLE 2. Variables significantly associated with participation in the Women's Centre of Jamaica Foundation Programme, study of prevalence of contraceptive use, Jamaica, 1994-1998a

\begin{tabular}{|c|c|c|c|c|c|c|}
\hline \multirow[b]{2}{*}{ Variable $^{a}$} & \multicolumn{2}{|c|}{$\begin{array}{l}\text { Participants } \\
\quad(n=87)\end{array}$} & \multicolumn{2}{|c|}{$\begin{array}{l}\text { Nonparticipants } \\
\quad(n=173)\end{array}$} & \multirow[b]{2}{*}{ Chi-square } & \multirow[b]{2}{*}{$P$ value } \\
\hline & No. ${ }^{b}$ & $\%^{c}$ & No. ${ }^{b}$ & $\%^{c}$ & & \\
\hline Family life educ. at home & & & & & 6.80 & 0.01 \\
\hline Yes & 52 & 60 & 73 & 43 & & \\
\hline No & 34 & 40 & 96 & 56 & & \\
\hline $\begin{array}{l}\text { Contraceptive use after } \\
\text { first live birth }\end{array}$ & & & & & 4.13 & 0.04 \\
\hline $\begin{array}{l}\text { Yes } \\
\text { No }\end{array}$ & $\begin{array}{r}80 \\
5\end{array}$ & $\begin{array}{r}94 \\
6\end{array}$ & $\begin{array}{r}147 \\
25\end{array}$ & $\begin{array}{l}86 \\
14\end{array}$ & & \\
\hline Repeat pregnancy & & & & & 14.31 & $<0.001$ \\
\hline Yes & 32 & 37 & 104 & 60 & & \\
\hline No & 55 & 63 & 69 & 40 & & \\
\hline
\end{tabular}

a The time frame for the different variables is as follows: family life education at home prior to first live birth in 1994; contraceptive use after first live birth in 1994; repeat pregnancy during follow-up period from January 1995 through December 1998.

${ }^{b}$ The number totals may not add up to the respective $n$ figures due to exclusion of missing values.

c Percents may not add up to 100 due to rounding and/or exclusion of missing values.

TABLE 3. Type of contraceptive method used after first live birth (1994) by teenage mothers who were participating and who were not participating in the Women's Centre of Jamaica Foundation Programme, study of prevalence of contraceptive use, Jamaica, 1994-1998

\begin{tabular}{|c|c|c|c|c|c|c|}
\hline \multirow[b]{2}{*}{ Method used } & \multicolumn{2}{|c|}{$\begin{array}{l}\text { Participating } \\
(n=87)\end{array}$} & \multicolumn{2}{|c|}{$\begin{array}{l}\text { Not participating } \\
\quad(n=173) \\
\end{array}$} & \multicolumn{2}{|c|}{$\begin{array}{c}\text { Total } \\
(n=260)\end{array}$} \\
\hline & No. ${ }^{a}$ & $\%{ }^{b}$ & No. ${ }^{a}$ & $\%{ }^{\mathrm{b}}$ & No. $^{\mathrm{a}}$ & $\%$ \\
\hline None & 5 & 6 & 25 & 15 & 30 & 11.6 \\
\hline Depo-Provera/Other injectable & 17 & 20 & 32 & 18 & 49 & 19.0 \\
\hline Condom & 14 & 17 & 22 & 13 & 36 & 14.0 \\
\hline Contraceptive pill & 25 & 29 & 82 & 47 & 107 & 41.5 \\
\hline IUD/Coil & 23 & 27 & 2 & 1 & 25 & 9.7 \\
\hline Withdrawal & 1 & 1 & 10 & 6 & 11 & 4.2 \\
\hline
\end{tabular}

\footnotetext{
a The number totals may not add up to the respective $n$ figures due to exclusion of missing values.
}

b Percentages may not add to 100 due to rounding and/or exclusion of missing values. ment, employment, and wages and salaries and that they also experienced fewer subsequent pregnancies. Chevannes also calculated that in 1993 Jamaica received an impressively high 6.7 to 1 benefit-to-cost return for its investments in the Women's Centre.

A study done by the Population Council INOPAL Project (18) compared WCJF graduates with a matched sample of teenagers who were not exposed to the Centre's program or any other, similar program. That research indicated that even though repeat pregnancy was a serious threat to all adolescent mothers, WCJF graduates were more likely to return to school, to use contraception, and to avoid additional pregnancies.

Our results are consistent with these earlier studies in demonstrating the very real value of counseling, both in enhancing knowledge of contraceptive methods and in influencing the critical choice of more effective methods. However, despite the best efforts of the WCJF program, repeat pregnancy continues to pose a serious threat to all Jamaican adolescent mothers. This is evidenced by the fact that $37 \%$ of program participants experienced a repeat pregnancy during the follow-up period, and also $29 \%$ of participants and $30 \%$ of nonparticipants reported using no contraceptive method at the time of last intercourse in 1998.

Despite early initiation of sexual activity, the highest level of contraceptive use that this study found, $88.3 \%$, was after the respondents' first live birth, a period when their perception of vulnerability to pregnancy was probably most acute. At the time of last intercourse, however, only $69 \%$ of the respondents used any contraceptive technique. These results offer strong support to the view of Hewell and Andrews (8) that adolescents' perception of risk-rather than the actual risk-determines contraceptive use.

Contraceptive use is recognized to be an independent predictor of pregnancy. In this study, when WCJF program status and other sociodemographic variables were held constant, contraceptive use at last intercourse was found to be an independent pre- 
TABLE 4. Contraceptive method used at last intercourse (1998) by teenage mothers who were participating and who were not participating in the Women's Centre of Jamaica Foundation Programme, study of prevalence of contraceptive use, Jamaica, 1994-1998

\begin{tabular}{|c|c|c|c|c|c|c|}
\hline \multirow[b]{2}{*}{ Method used } & \multicolumn{2}{|c|}{$\begin{array}{l}\text { Participating } \\
\quad(n=87)\end{array}$} & \multicolumn{2}{|c|}{$\begin{array}{l}\text { Not participating } \\
\quad(n=173)\end{array}$} & \multicolumn{2}{|c|}{$\begin{array}{c}\text { Total } \\
(n=260)\end{array}$} \\
\hline & No. ${ }^{a}$ & $\%^{b}$ & No. ${ }^{\mathrm{a}}$ & $\%^{b}$ & No. ${ }^{a}$ & $\%^{b}$ \\
\hline None & 25 & 29 & 51 & 30 & 76 & 30.0 \\
\hline Depo-Provera/Other injectable & 24 & 27 & 63 & 38 & 86 & 34.0 \\
\hline Condom & 16 & 18 & 23 & 14 & 38 & 15.0 \\
\hline Contraceptive pill & 11 & 13 & 23 & 14 & 34 & 13.4 \\
\hline IUD/Coil & 10 & 12 & 3 & 2 & 13 & 5.1 \\
\hline Withdrawal & 1 & 1 & 5 & 3 & 6 & 0.4 \\
\hline
\end{tabular}

a The number totals may not add up to the respective $n$ figures due to exclusion of missing values.

b Percentages may not add to 100 due to rounding and/or exclusion of missing values.

TABLE 5. Contraceptive use variables significantly associated with repeat pregnancy for total sample of 260 participants in study of prevalence of contraceptive use, Jamaica, 1994-1998

\begin{tabular}{|c|c|c|c|c|c|c|}
\hline \multirow[b]{2}{*}{ Variable } & \multicolumn{2}{|c|}{$\begin{array}{c}\text { Repeat } \\
\text { pregnancy } \\
(n=136)\end{array}$} & \multicolumn{2}{|c|}{$\begin{array}{c}\text { No repeat } \\
\text { pregnancy } \\
(n=124)\end{array}$} & \multirow[b]{2}{*}{ Chi-square } & \multirow[b]{2}{*}{$P$ value } \\
\hline & No. ${ }^{a}$ & $\%^{b}$ & No. ${ }^{a}$ & $\%^{b}$ & & \\
\hline \multicolumn{7}{|l|}{ Contraceptive use at last } \\
\hline Yes & 82 & 63 & 93 & 76 & & \\
\hline No & 49 & 37 & 29 & 24 & & \\
\hline \multicolumn{7}{|c|}{ Type of contraception used } \\
\hline $\begin{array}{l}\text { at last intercourse } \\
\text { No method }\end{array}$ & 47 & 36 & 29 & 24 & 19.05 & $<0.01^{\mathrm{C}}$ \\
\hline Contraceptive pill & 13 & 10 & 21 & 17 & & \\
\hline Condom & 16 & 12 & 22 & 18 & & \\
\hline IUD or coil & 1 & 1 & 12 & 10 & & \\
\hline \multicolumn{7}{|l|}{ Depo-Provera or other } \\
\hline Withdrawal & 4 & 3 & 2 & 1 & & \\
\hline \multicolumn{7}{|c|}{ Contraceptive use after first } \\
\hline live birth (1994) & & & & & 5.89 & 0.02 \\
\hline Yes & 113 & 84 & 114 & 93 & & \\
\hline No & 22 & 16 & 8 & 7 & & \\
\hline \multicolumn{7}{|c|}{ Type of contraception used } \\
\hline after first live birth & & & & & 29.49 & $<0.01^{c}$ \\
\hline No method & 22 & 16 & 8 & 7 & & \\
\hline Contraceptive pill & 63 & 47 & 44 & 36 & & \\
\hline Condom & 15 & 11 & 21 & 17 & & \\
\hline IUD or coil & 3 & 2 & 22 & 18 & & \\
\hline \multicolumn{7}{|l|}{ Depo-Provera or other } \\
\hline inject. contracept. & 23 & 17 & 26 & 21 & & \\
\hline Withdrawal & 9 & 7 & 2 & 1 & & \\
\hline
\end{tabular}

a The number totals may not add up to the respective $n$ figures due to exclusion of missing values.

b Percents may not add up to 100 due to rounding and/or exclusion of missing values.

${ }^{c}$ At least one cell has an expected count less than 5 . dictor of repeat pregnancy, reducing its incidence among this study population by $43 \%$. However, participation in the WCJF program was only significantly associated with contraceptive use after the first live birth, and not at last intercourse.

The WCJF program has been recognized internationally as a model for the prevention of repeat adolescent childbearing, and it has attracted considerable interest in several other Caribbean and African countries. Although the overall incidence of repeat pregnancy among WCJF program participants was far lower than among nonparticipants $(37 \%$ vs. $60 \%)$, much more attention needs to be given to educating participants, and indeed all adolescent females and males, about effective contraceptive use. The major challenge to the WCJF in coming years will be to sustain the momentum of the program as well as to extend its benefits to more adolescents. First-time and repeat pregnancy throughout Jamaica will be substantially reduced only through effective contraception. Additional research is needed to look at the array of services provided in the WCJF program and to assess the best ways of sustaining effective use of contraception among adolescent males and females. 


\section{REFERENCES}

1. McNeil P, Olafson P, Powell D, Jackson J. The Women's Centre in Jamaica: an innovative project for adolescent mothers. Stud Fam Plann 1983;14(5):143-149.

2. The Women's Centre of Jamaica Foundation. Annual Report 1994. Kingston: The Women's Centre of Jamaica Foundation; 1995.

3. Jagdeo T. The dynamics of adolescent fertility in the Caribbean. St. John's, Antigua: Caribbean Family Planning Affiliation; 1992.

4. Chevannes B. Sexual behavior of Jamaicans: a literature review. Soc Econ Stud 1993;42(1): $1-45$.

5. National Family Planning Board. 1993 contraceptive prevalence survey Jamaica. Volume IV: sexual behavior and contraceptive use among young adults. Atlanta, Georgia, United States of America: Centers for Disease Control and Prevention; 1995.

6. Jagdeo T. Teenage pregnancy in the Caribbean. New York: International Planned Parenthood Federation, Western Hemisphere Region; 1984.

7. Russell-Brown P, Rice J, Hector O, Bertrand J. The effect of sex education on teenagers in St.
Kitts and Nevis. Bull Pan Am Health Organ 1992;26(1):67-79.

8. Hewell S, Andrews J. Contraceptive use among female adolescents. Clin Nurs Res 1996;5(3):356-363.

9. Johns Hopkins School of Public Health, Center for Communication Programs, Population Information Program. Family planning lessons and challenges: making programs work. Population Reports 1994;22(2):1-32.

10. Setiloane $C$. Contraceptive use amongst urban and rural youths in South Africa-a comparative study. Curationis 1990;13(3-4):44-48.

11. Alade MO. Teenage pregnancy in Ile-Ife, Western Nigeria. West J Nurs Res 1989;11(5): 609-613.

12. Herold E. Teenage sexuality and sexual health. Can J Public Health 1994; 85(4): 223-224.

13. Villar J, Ezcurra E, Perez-Palacios G, Hogue C de la Fuente VG. Expanding research capacities to improve reproductive health in the Americas. Geneva: World Health Organization; 1994. (Publication WHO/HRP/RFR/ 1994).
14. Population Reference Bureau; Demographic and Health Surveys Macro Inc.; Centers for Disease Control and Prevention. Adolescent sexual activity and childbearing in Latin America and the Caribbean: risks and consequences. Washington, D.C.: Population Reference Bureau; 1992.

15. Statistical Institute of Jamaica. Statistical yearbook of Jamaica. Kingston, Jamaica: STATIN 1996.

16. Brown J. The Women's Centre of Jamaica Foundation: tracer study of ex-participants of the WCJF program. Kingston, Jamaica: The Women's Centre of Jamaica Foundation; 1995.

17. Chevannes B. The Women's Centre of Jamaica Foundation Programme for Adolescent Mothers: an evaluation. Kingston, Jamaica: The Women's Centre of Jamaica Foundation; 1996.

18. The Population Council, INOPAL Project. Jamaica: teen mothers return to school. Alternatives; September 1989:2, 4, 9.

Manuscript received 17 January 2002 and accepted for publication 23 January 2002.

RESUMEN Objetivos. Comparar la prevalencia del uso de anticonceptivos entre madres adolescentes que estaban participando o no en un programa instaurado en Jamaica para abordar el grave problema que en este país representan los embarazos repetidos en adolescentes.

\section{Uso de anticonceptivos por madres adolescentes jamaiquinas}

Métodos. Se usó un diseño de cohorte histórica para evaluar el impacto del Programa para Madres Adolescentes del Centro de Mujeres de la Fundación Jamaica (The Women's Centre of Jamaica Foundation: WCJF) sobre el uso de anticonceptivos en la población de adolescentes de 16 años o menos que habían tenido su primer niño vivo en 1994.

Resultados. El uso de anticonceptivos en el primer coito fue más frecuente entre las participantes en el programa del WCJF (44\%) que entre las que no participaron (37\%), pero la diferencia no fue significativa $(P=0,35)$. El uso de anticonceptivos tras el nacimiento del primer niño vivo también fue mayor entre las participantes en el programa $(94 \%)$ que entre las que no participaron $(86 \%)$, y esta diferencia fue significativa $(P=0,04)$. La prevalencia del uso de anticonceptivos en el último coito (en 1998) fue igual en ambos grupos (69\%).

Conclusiones. El uso de anticonceptivos en esta población jamaiquina fue más frecuente cuando la percepción de las encuestadas de su vulnerabilidad al embarazo era más aguda, esto es, después del nacimiento del primer niño vivo. Es necesario educar a todos los adolescentes de ambos sexos acerca de la importancia del uso continuo y eficaz de anticonceptivos, con el fin de reducir el riesgo de embarazos no deseados y de enfermedades de transmisión sexual. 